\title{
Laser-produced plasma EUV source based on tin-rich, thin-layer targets
}

\author{
R. Rakowski • J. Mikołajczyk • A. Bartnik • \\ H. Fiedorowicz · F. de Gaufridy de Dortan • R. Jarocki • \\ J. Kostecki • M. Szczurek • P. Wachulak
}

Received: 24 April 2010 / Revised version: 25 July 2010 / Published online: 15 September 2010

(C) The Author(s) 2010. This article is published with open access at Springerlink.com

\begin{abstract}
In this paper a new approach to a laser-produced plasma EUV source based on a tin target is presented. A thin layer of pure tin and composite layers consisting of $\mathrm{Sn}$ with $\mathrm{Si}, \mathrm{SiO}$ and $\mathrm{LiF}$ are investigated. The target composed of several thin layers produces less debris than the other targets and provides a conversion efficiency (CE) in the $13.5-\mathrm{nm} \pm 1 \%$ band at least comparable to the $\mathrm{CE}$ for the pure tin slab target. The largest CE was observed for the target composed of a mixture of $\mathrm{Sn}$ and $\mathrm{LiF}$, due to the fact that lithium, similarly to tin, is a strong emitter at $13.5 \mathrm{~nm}$.
\end{abstract}

\section{Introduction}

EUV sources based on laser-produced plasmas using masslimited targets are believed to be capable of meeting basic EUV lithography (EUVL) requirements: high conversion efficiency (CE) as well as cleanliness of the source [1-4]. In

\footnotetext{
R. Rakowski (凶) · J. Mikołajczyk · A. Bartnik · H. Fiedorowicz R. Jarocki · J. Kostecki · M. Szczurek · P. Wachulak Institute of Optoelectronics, Military University of Technology, 2 Gen. Sylwestra Kaliskiego St., 00-908 Warsaw, Poland e-mail: rafal.rakowski@post.pl Fax: +48-22-6668950

Present address:

R. Rakowski

Department of Physics, Lund University, Lund, Sweden

F. de Gaufridy de Dortan

Service des Photons, Atomes et Molecules, CEA-Saclay, 91191 Gif-sur-Yvette Cedex, France

P. Wachulak

Department of Electrical and Computer Engineering, Colorado State University, 1320 Campus Delivery, Fort Collins, CO 80523-1320, USA
}

the infancy of seeking targets suited as EUV sources, the following candidates were considered: $\mathrm{Li}, \mathrm{F}, \mathrm{Sc}, \mathrm{Sn}, \mathrm{I}$, and Xe. At present the only contenders are lithium, tin and xenon due to the well controlled technology of their preparation and the existence of highly reflective multi-layer optics [5].

Plasma that contains tin ions is characterized by a relatively high radiation intensity in the EUV range. The spectral distribution of the radiation in an unresolved transition array (UTA) is rather wide with the maximum at around $13.5 \mathrm{~nm}[6,7]$. At the beginning of the development of laserplasma EUV sources, the tin target was in the form of a thin foil or sheet of metal [8-10]. The theoretical analysis has shown that a target made solely of tin is ineffective because the ionic concentration in the plasma is too high. This results from two mutually compensating physical processes: radiation emission and self-absorption [11]. Therefore, a solid target composed of several percent of tin atoms in a ceramic matrix containing low atomic number elements $(\mathrm{Li}, \mathrm{B}, \mathrm{O}$, and $\mathrm{Si}$ ) has been suggested. The application of such a composite target has assured a twofold growth of the conversion efficiency [12-14].

This effect is similar to using a prepulse [15]. For the solid-state targets like tin, two important advantages of applying the prepulse can be distinguished. The first consists in creating, by means of the prepulse, low-density plasma. This is advantageous from the self-absorption point of view, because that type of plasma is optically thin. The expanding plasma is the target for the main pulse. The second advantage concerns a significantly smaller amount of material particles ejected. The prepulse directly influences the surface of the solid target in a relatively short time and thus reduces the thermally induced degradation of the surface. In the prepulse case, the density profile of the generated plasma is dependent on the delay between the two pulses and on the relative pulse energies as well [16]. At $13.5 \mathrm{~nm}$ an intensity 
increase of $70 \%$ has been observed, when the prepulse was delayed by several ns with respect to the main pulse [10].

Tin and lithium have relatively high conversion efficiencies; still, they can cause condensation of material ejected from the plasma on the surface of the EUV optics. To overcome this limitation, the usage of an inert gas (Xe) was suggested [17, 18]. The maximum conversion efficiencies found so far are 5\% for targets containing tin atoms (tin-rich liquid jet) [19], 3\% for lithium targets [20], and $1.4 \%$ for xenon targets (solidified xenon) [21]. The debris-free double-stream $\mathrm{Xe} / \mathrm{He}$ gas-puff target reaches $0.43 \%$ CE (R. Rakowski, et al., to be published). The literature reports the possibility of increasing the conversion efficiency up to $6 \%$ for tin target $[22,23]$. Presumably, tin-based plasma might be utilized for 13.5-nm lithography, because it exceeds the demanded $3 \%$ CE [11, 24]. Nevertheless, solid-state targets produce a lot of contaminants and debris (droplets, ions) from the exposed surface that cause devastation of either the glass or the $\mathrm{X}$-ray optical elements. This ejected particle stream has to be mitigated to extend optics lifetime and to show the usefulness of solid-based targets for EUV technology [3, 25-27]. Measurements conducted with a single laser pulse at a distance of $5 \mathrm{~cm}$ from the plasma showed that the solid target sources emit debris material of up to $1 \mu \mathrm{g} / \mathrm{cm}^{2}$ [28].

Searching for how to increase the CE and reduce the amount of ejected material from tin, new ideas for the target have come up. One proposition is to use a tape target, which produces less debris and minimizes the material evaporation [3, 29-32]. In the area of the target interaction with a laser pulse, mass-limited targets undergo a full ionization assuring the proper density of tin ions and ionic fraction. This eliminates self-absorption of the EUV radiation through strongly absorbing, lowly ionized plasma regions. Additionally, mass-limited targets produce two orders of magnitude less debris, because the target quantity is limited to the amount needed for efficient EUV emission only [29,33]. In one of the experiments, the target was a liquid pure tin stream [34], in another layers of $\mathrm{SnO}_{2}$ powder were utilized leading to a fourfold increase of the $\mathrm{CE}$ in relation to a tin foil [35], in some other experiments globules made of plastic material coated by a tin layer [36] or targets made of a porous material containing tin at reduced density were used [37]. All the solutions for the target design mentioned above aimed at gaining high CEs by using a target of appropriate tin density. Moreover, the homogeneous exposure of a spherical tin target using twelve simultaneous laser pulses was also demonstrated [38]. However, the highest CE obtained so far was achieved with a liquid stream containing tin (5\% as mentioned above). The tin content by mass was up to a few tens of percent $[39,40]$. Similar experiments were conducted in the Institute of Optoelectronics between 2005 and 2006. They were motivated by the expectation to find novel materials for the targets resulting in maximizing tolerably debris-free, EUV in-band radiation. During these experiments, apart from a liquid target, various compositions of materials containing tin and lithium atoms in form of thin layers deposited on glass or silicon substrates were studied.

In recent years efforts aimed at the reduction or even the elimination of the damaging stream of material particles ejected from the plasma have been intensified. This is due to the requirement for increasing the lifetime of EUV optical elements. The experiments included, amongst others, the conception of blocking the emission of particles by means of electric fields, protective gas with a particle trap or using the double plasma [41-44]. Targets made from tin and lithium have failed so far to entirely eliminate the damaging activity of the particles ejected from the target without considerably decreasing the EUV emission.

The goal is that the reflective optics can be exposed to the $13.5-\mathrm{nm}$ radiation for 30,000 hours, meeting the condition that the irreversible relative decline of the reflection coefficient is $\leq 1 \%$ [4]. However, this lifetime requirement involves a debris-free source. But even in this case the mirrors lose their high reflectivity due to the long-lasting exposure of EUV radiation. The decrease is connected to carbon atoms and silicon oxides drifting on the silicon surface. The active carbon and oxygen particles are created on the mirror surface as the result of the disintegration (dissociation) of hydrocarbons, carbon dioxide, water and oxygen molecules under the influence of radiation and secondary electrons $[4,45]$. The source of these unwanted impurities is outgassing from the resist and cables and the residual gas atmosphere in the vacuum chamber (EUV optics cannot be heated to assure high vacuum). Carbon layers are less dangerous than oxides because those layers are evaporated during the interaction of the EUV radiation pulse with the mirror surface. Therefore, the process of reflectivity lowering resulting from the drift of carbon-layers is recoverable.

The additional presence of the debris significantly reduces optics lifetime. Ion implantation in a mirror layer of nanometer thickness could occur [46]. Moreover, it has been demonstrated that a single Mo/Si layer pair is sputtered away by fast ions within $1.5 \times 10^{7}$ shots resulting in the lifetime of 726 light-on hours $[47,48]$. The amount of debris production from solid-tin targets is proportional to the laser power. The laser power of the order of $\mathrm{kW}$ needed for industrial EUV lithography will result in greater target-particle production compared to that used in our experiment (laser power $\sim 10 \mathrm{~W}$ ). The most successful scheme of the EUV source approaching the required intermediate focus point power of $115 \mathrm{~W}$ has turned out to be the combination of a tin droplet target (kind of mass-limited) irradiated with a $\mathrm{CO}_{2}$ laser using the prepulse technique $[49,50]$. This also minimizes the debris problem. There is much reduced debris production with the use of this laser compared to the Nd:YAG 
due to a different interaction condition, and, additionally, the magnetic field mitigation has been applied in that approach [50, 51]. Perhaps using the $\mathrm{CO}_{2}$ laser and the efficient debris mitigation system might make feasible the target based on solid-tin for EUV lithography. The development of a tin-rich, thin-layer tape target could still improve mainly through CE increase, the laser-produced plasma EUV source for EUVL.

The purpose of the present paper is to compare pure tin targets and targets composed of layers containing tin, silicon, silicon oxide, and lithium fluoride as to $\mathrm{CE}$ and debris production and to identify which target performs best. The paper is organized as follows. Section 2 describes the experimental conditions. Section 3 deals with the spectral measurements and Sect. 4 with the absolute measurement of the EUV pulse energy. Section 5 investigates the debris production. Section 6 contains the conclusion with an outlook on possible further studies.

\section{Experimental conditions}

In our study a Nd:YAG laser (energy per pulse $E=0.85 \mathrm{~J}$, pulse duration $t=3.1 \mathrm{~ns}$ (FWHM), repetition rate up to $10 \mathrm{~Hz}$ ) was utilized. The experiments were performed in a vacuum chamber evacuated to $5 \times 10^{-6}$ mbar. The targets consist of a thin layer containing tin atoms which is deposited on a microscope glass slide $1 \mathrm{~mm}$ thick or on a silicon wafer $0.3 \mathrm{~mm}$ thick. Various thicknesses of the pure tin layer were investigated: $10 \mathrm{~nm}, 100 \mathrm{~nm}, 200 \mathrm{~nm}, 500 \mathrm{~nm}$, $1000 \mathrm{~nm}$, and $1500 \mathrm{~nm}$, respectively. Besides the pure tin layers, also layers containing tin in volumes of other materials like $\mathrm{LiF}$ (6.2\% of $\mathrm{Sn}$ by volume), $\mathrm{SiO}$ (12\% of $\mathrm{Sn}$ by volume) or $\mathrm{Si}$ ( $10 \% \mathrm{Sn}$ by volume) were deposited on the substrate and studied. Moreover, for $\mathrm{LiF}$ with a $\mathrm{Sn}$ target a multilayer of $17-\mathrm{nm}$ thick $\mathrm{Sn}$ and 120 -nm thick LiF with a total thickness of about $1.5 \mu \mathrm{m}$ was deposited on a glass substrate. The spectral and absolute measurements of the EUV radiation were carried out at the incidence angle of 45 degrees.

A justifiable question concerns the laser pulse parameters: wavelength, duration, and power density being most important in transforming laser energy into EUV radiation effectively. For the laser wavelength used, due to plasma expansion in vacuum and a connected decrease of electron concentration, only the first 5-10 ns of the laser pulse will be efficiently absorbed [3, 29]. Too short a pulse duration, e.g., in the range of picoseconds, is ineffective because of the maladjustment to the characteristic duration of atomic processes occurring during the absorption of the laser energy in plasma [52]. The optimum electron temperature for efficient EUV emission is in the $20-50 \mathrm{eV}$ region and is proportional to the laser power density (irradiance) per pulse and the laser wavelength [53]. The optimum power density for the Sn plasma and Nd:YAG laser wavelength is estimated to be $\sim 10^{11} \mathrm{~W} / \mathrm{cm}^{2}$ to assure optimal conversion efficiency. This determines the window range of the laser pulse energy and focal spot size which are complementary to some extent. However, the focus size is limited to some extent with regard to the absorption of the laser radiation and its adjustment to plasma expansion [8]. In order to yield the desired power density, laser pulses of $0.1-10 \mathrm{~J}$ are focused to a spot size from a few tens to one hundred microns in the Nd:YAG laser case. A natural way to scale up the EUV output to that required for EUV lithography is to increase the repetition rate of the laser. But that is also challenging for solid-state lasers when approaching $10 \mathrm{kHz}$. Nevertheless, it could compensate the small pulse energy which is beneficial from the lower debris production point of view.

The possibility of applying laser sources with shorter and longer wavelengths has been also considered. Pulses of shorter wavelength are better absorbed by plasma. Furthermore, they reach plasma areas of higher density because the value of the plasma density beyond which a wave is reflected, is proportional to $1 / \lambda^{2}$. However, locating the absorption of laser energy into deeper located plasma areas which are simultaneously characterized by a strong self-absorption does not increase the $\mathrm{CE}$ of laser energy in EUV radiation. Applying a pulse with a shorter wavelength would be reasonable if it were possible to control the plasma density [11]. When our experiment was performed it was demonstrated that lasers with a longer wavelength, e.g., $\lambda=10.6 \mu \mathrm{m}\left(\mathrm{CO}_{2}\right.$ laser $)$, led to values of the $\mathrm{CE}$ comparable to those obtained with Nd:YAG lasers $[54,55]$. However, it was recently reported that by using a $\mathrm{CO}_{2}$ laser of $7.9 \mathrm{~kW}$ and $100-\mathrm{kHz}$ repetition rate, the CE increased several times and the EUV yield approached the desired value $[50,51,56]$.

\section{Spectral measurements}

The spectral properties of the EUV emission were investigated using a $0.25-\mathrm{m}$ grazing incidence spectrograph with a variable-pitch grating (Hitachi prod. [57, 58]). The spectra were recorded in single-shot operation with an automatic background subtraction. In order to compare with the results obtained for thin-layer targets, the spectral images and distributions for pure tin targets in form of a $9 \mu \mathrm{m}$ thick foil and a $4 \mathrm{~mm}$ thick sheet were measured (see Fig. 1). It is evident that the profile width (FWHM) of the UTA peak is wider in the case of the foil target ( $\sim 4 \mathrm{~nm}$ wide) in comparison to the slab target ( $\sim 2 \mathrm{~nm}$ wide). This indicates greater electron density for the slab target and, in consequence, higher EUV opacity and hence higher electron temperature. At higher temperature the Planck limit is greater (the maximal 
Sn sheet

Sn foil
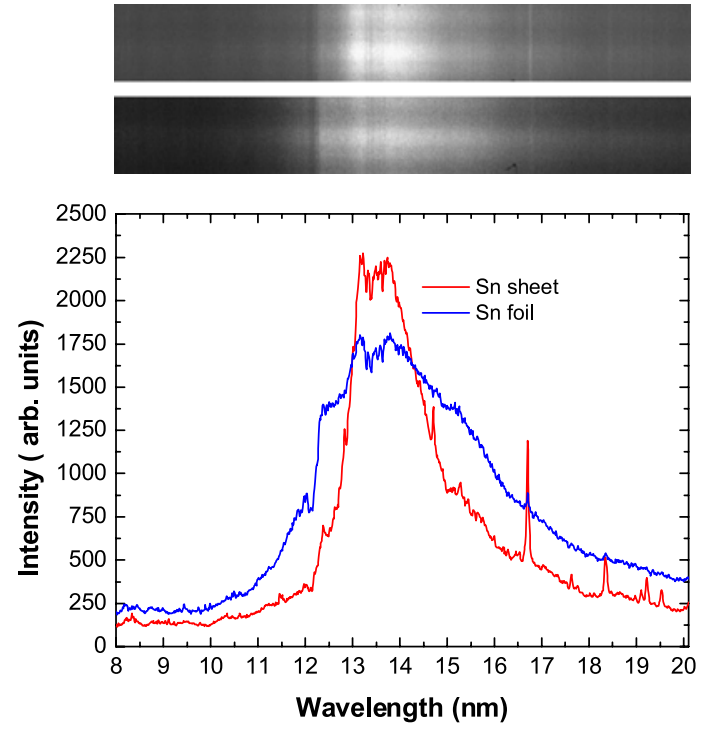

Fig. 1 EUV spectra from tin targets: a 9- $\mu \mathrm{m}$ thick foil (blue), a 4-mm thick sheet $(\mathrm{red})$

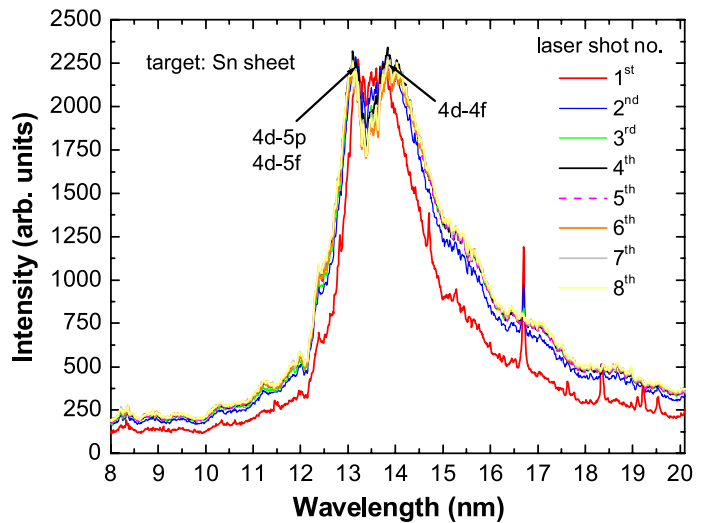

Fig. 2 EUV spectra from a tin sheet for eight successive laser shots on the same crater

emission attainable for the specific spectral region), but simultaneously a smaller plasma region efficiently radiates at $13.5 \mathrm{~nm}$. Thus the EUV in-band ( $13.5 \mathrm{~nm} \pm 1 \%)$ emission of the foil target was effectively lower than that of the sheet tin target. During the laser-target interaction, the tin foil was entirely evaporated, while the surface of the slab target was almost intact. The origin of the narrower and higher UTA peak of the slab target derives probably from the laser pulse interaction with the target surface coated with oxidants, which modify the absorption of the EUV. The confirmation comes from Fig. 2, where the spectral distributions for a slab target for successive laser shots onto the same crater are presented.

Evidently, the width of the spectral peak obtained for the first laser shot is the narrowest. The appearance of single lines visible in the spectrum, situated on the long wavelength side of the UTA peak, also confirms the presence

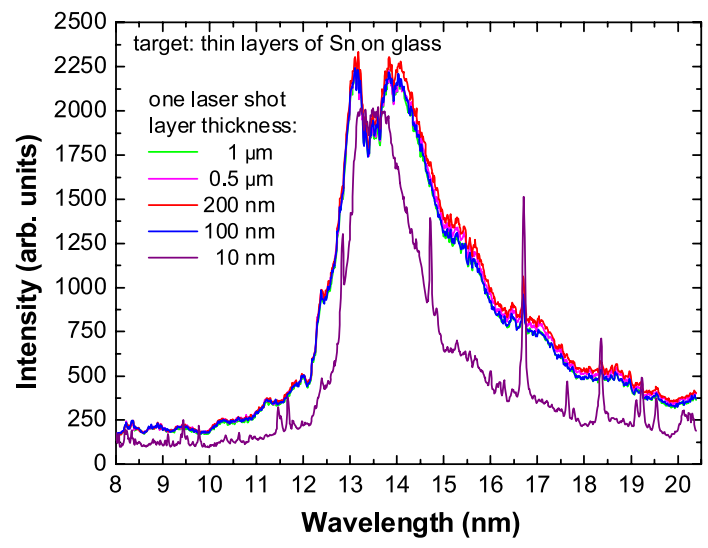

Fig. 3 EUV spectra from thin tin layers deposited on a glass substrate

of surface contaminants. The observable double peak of the UTA, corresponding to transitions $4 d-5 f+4 d-5 p$ and $4 \mathrm{~d}-4 \mathrm{f}$ is characteristic for the electron temperature considerably exceeding the temperature for the optimum emission at $13.5 \mathrm{~nm}$ of the order of $40 \mathrm{eV}$ (for which one obtains a single UTA peak). In another experiment using the Nd:YAG laser with the same pulse energy, but with a 5 times longer pulse duration enabling a lower electron temperature, a greater CE and a more uniform shape of the UTA peak was achieved.

The tin thin-layer targets of various thicknesses were investigated in order to find the appropriate layer thickness necessary to reduce the electron density and the opacity associated with it that is responsible for decreasing the EUV emission. The spectral results of EUV intensity emission for different thicknesses of the target are presented in Fig. 3.

The highest in-band EUV emission was recorded for a layer thickness of $200 \mathrm{~nm}$, but the intensity was only slightly higher compared to that of the 100-nm thick layer. For thicknesses greater than $200 \mathrm{~nm}$, the spectra look very similar. For the thinnest layer of 10 -nm thickness, the UTA spectrum was narrower with lower intensities indicating an electron density that was too low due to an insufficient amount of target material. The additional peaks seen in the EUV spectrum coming from the substrate material confirm this conclusion. In Fig. 4 the evolution of the spectra for successive laser shots and selected target thicknesses is presented.

It is worth to notice the lack of the EUV emission for the second laser shot on the 100-nm thick target, while the emission for the first laser shot was comparable to the emission for the 200-nm thick target. This indicates that the entire target material for the 100-nm thick layer was evaporated in the first shot. In this sense the 100-nm tin layer target had an optimum thickness.

In Fig. 5 the evolution of the EUV spectra for eleven successive laser shots on the same spot is presented. The target 


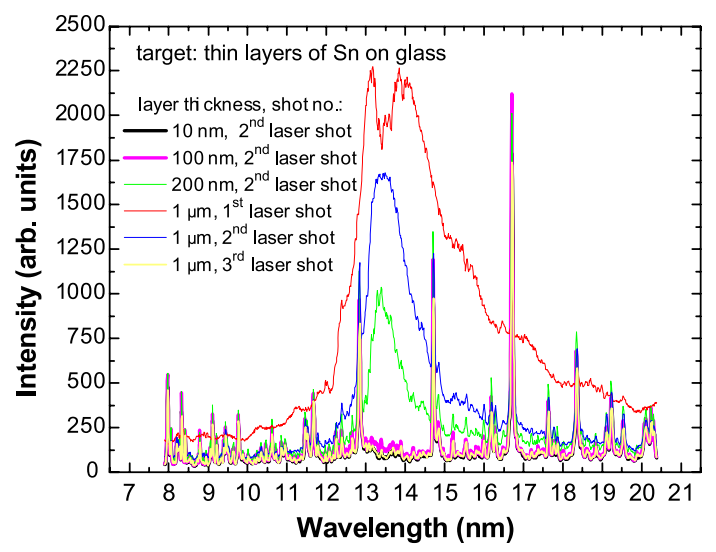

Fig. 4 EUV spectra from selected thin tin layers deposited on a glass substrate for the first three successive laser shots
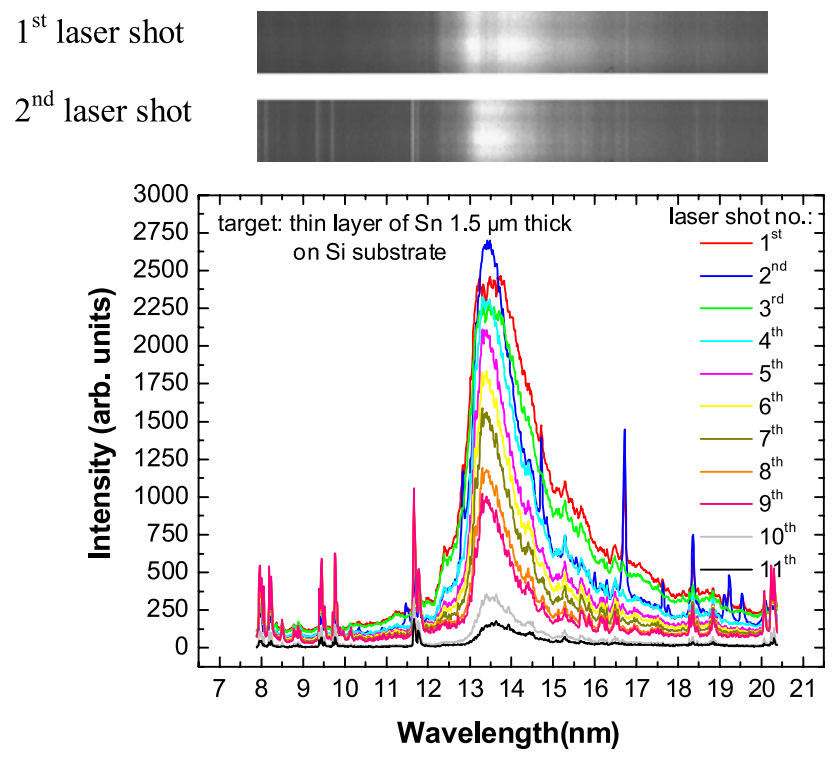

Fig. 5 EUV spectra from a 1.5- $\mu \mathrm{m}$ thick tin layer deposited on a $\mathrm{Si}$ substrate for eleven successive laser shots

consisted of a $1.5-\mu \mathrm{m}$ thick tin layer deposited on a silicon substrate. The peaks of UTA demonstrate higher intensity with a simultaneously slightly narrower spectral width in comparison to the emission from the tin layer deposited on the glass substrate.

Tin-rich, thin-layer targets were subsequently investigated. The spectra obtained for the first laser shot, for mixtures of tin with either $\mathrm{Si}$ or $\mathrm{SiO}$ deposited on glass, were comparable to those recorded for a thin tin layer deposited on silicon (see Fig. 6).

Another composite thin-layer target investigated consisted of Sn containing LiF deposited on glass. The targets were prepared in two different ways: as a homogeneous layer or as multilayer of $\mathrm{Sn}$ and $\mathrm{LiF}$. It is known that the lithium plasma is also a strong emitter of EUV radiation at

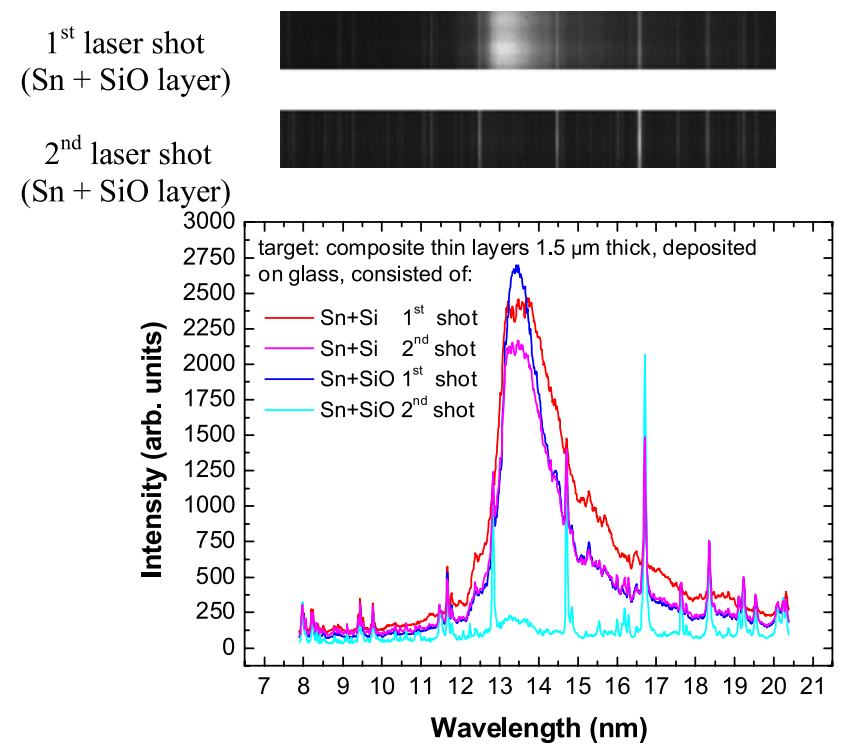

Fig. 6 EUV spectra from composite thin-layer targets: Sn with $\mathrm{Si}$ and $\mathrm{Sn}$ with $\mathrm{SiO}$ deposited on glass for the first two laser shots

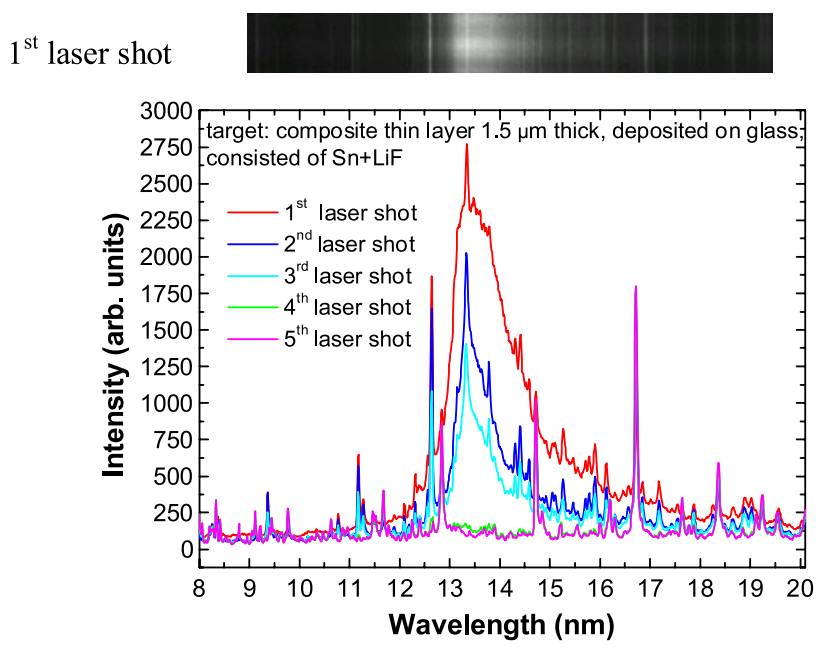

Fig. 7 EUV spectra from a target composed of a thin tin layer with $\mathrm{LiF}$ deposited on glass for the first five laser shots

$13.5 \mathrm{~nm}$. The spectra of these targets are presented in Fig. 7 and Fig. 8.

The EUV in-band emission from Li plasma derives from one transition only, $\mathrm{Ly}_{\alpha}$ from hydrogen-like (Li III) ions. For the target composed of tin with $\mathrm{LiF}$ (as separated alternating thin layers), the first laser shot only produces the lines from Li II, Li III and F V as seen in the EUV spectrum. For the second laser shot on the same spot, a superposition of lines at $13.5 \mathrm{~nm}$ coming from lithium and tin emissions dominate the spectrum. In the case of the targets consisting of a thin tin layer with LiF, the EUV in-band emission decreases significantly with a successive number of laser shots. 


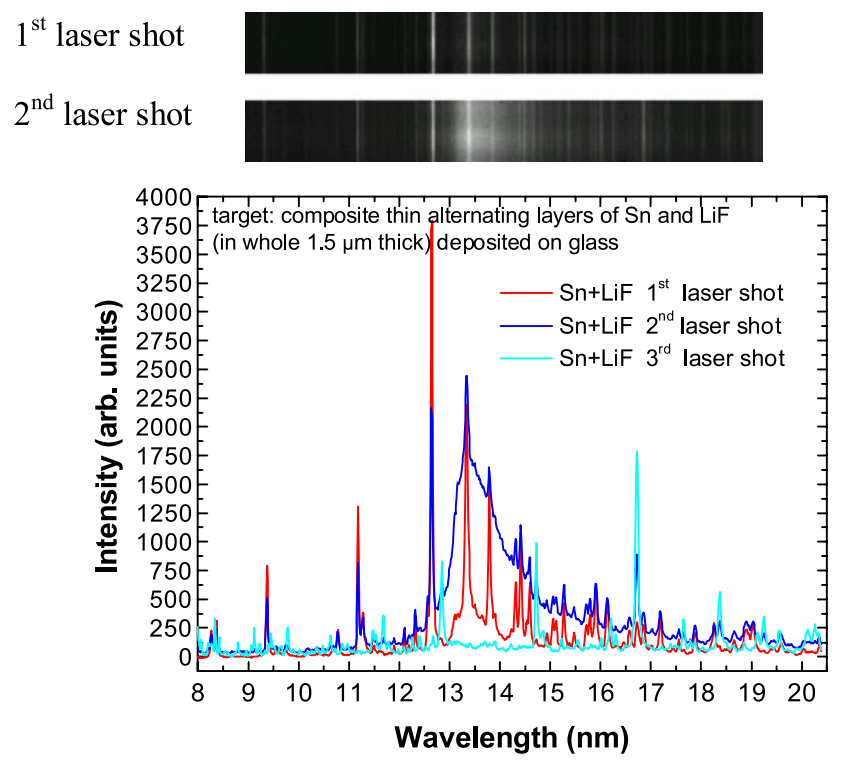

Fig. 8 EUV spectra from a target composed of a multilayer of Sn and $\mathrm{LiF}$ deposited on glass for the first three laser shots

Table 1 Conversion efficiencies obtained for investigated targets based on tin

\begin{tabular}{lll}
\hline Target & Average CE [\%] & $\sigma_{\mathrm{CE}}[\%]$ \\
\hline Sn sheet & 1.20 & 2.33 \\
$10 \mathrm{~nm}$ Sn layer on glass & 0.63 & 0.30 \\
$100 \mathrm{~nm}$ Sn layer on glass & 1.17 & 0.65 \\
$200 \mathrm{~nm}$ Sn layer on glass & 1.12 & 0.58 \\
$500 \mathrm{~nm}$ Sn layer on glass & 1.20 & 1.72 \\
$1 \mu \mathrm{m}$ Sn layer on glass & 1.23 & 1.13 \\
$1.5 \mu \mathrm{m}$ Sn layer on glass & 1.15 & 0.20 \\
$1.5 \mu \mathrm{m}$ Sn layer on silicon & 1.21 & 7.31 \\
$1.5 \mu \mathrm{m}$ Sn + SiO layer on glass & 1.45 & 2.99 \\
$1.5 \mu \mathrm{m} \mathrm{Sn} / \mathrm{LiF}$ layers on glass & 1.07 & 6.09 \\
$1.5 \mu \mathrm{m} \mathrm{Sn}+$ LiF layer on glass & 1.43 & 1.17 \\
\hline
\end{tabular}

\section{Absolute EUV pulse energy measurements}

Besides the spectral measurements, absolute measurements of the EUV pulse energy were carried out using a calibrated E-MON energy meter (Jenoptik prod., Jena). The results are summarized in Table $1\left(\sigma_{\mathrm{CE}}\right.$ is the standard deviation of the $\mathrm{CE}$ ). The highest $\mathrm{CE}$ was measured for the target consisting of a $1.5-\mu \mathrm{m}$ thick tin layer with $\mathrm{LiF}$ or $\mathrm{SiO}$ deposited on glass. An interesting effect was observed for the target consisting of a $1.5-\mu \mathrm{m}$ thick tin layer coated on $\mathrm{Si}$, where the EUV in-band intensity for the first laser shot was larger than that for the second, but smaller than those for the third and fourth shots.

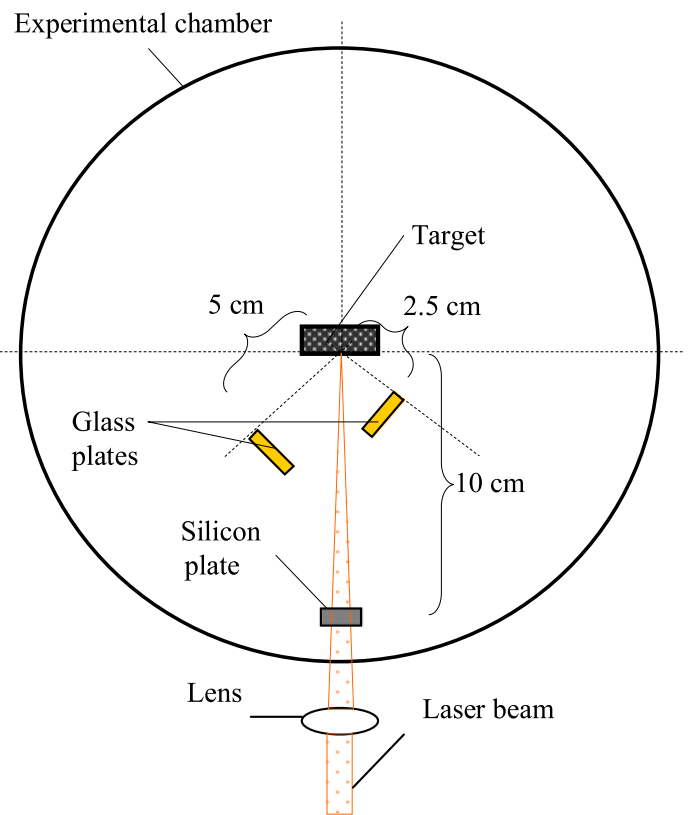

Fig. 9 Scheme of the set-up for investigating the influence of the EUV source on optics

\section{Debris stream investigations}

The debris (droplets, contaminants) originating from laserproduced plasma can harmfully affect the refractive and reflective (x-ray) optics [26]. The investigations of the material ejected from the EUV source based on thin-layer targets were performed with the use of witness plates. Glass microscope slides (imitate the refractive optics) as well as silicon wafers (imitate EUV optics) were utilized as the plates. The experimental geometry is presented in Fig. 9.

The glass or silicon samples were placed at distances of 2.5 and $5 \mathrm{~cm}$ from the plasma at the incidence angle of $45^{\circ}$. The silicon wafer was located at the distance of $10 \mathrm{~cm}$ slightly above the incoming laser beam. The studies were conducted for pure tin sheets and for thin-layer targets consisting of a uniform $1.5-\mu \mathrm{m}$ thick $(\mathrm{Sn} / \mathrm{LiF})$ layer deposited on glass. Those two different targets were subjected to the EUV exposure from 250 laser shots, displacing the target during the process to assure that each shot hits a fresh target surface. The photographs of the witness samples after interaction with the contaminants are presented in Fig. 10.

The two upper plates correspond to the pure tin target, the two lower ones to the $\mathrm{Sn} / \mathrm{LiF}$ target. The two plates on the left hand side were set at a distance of $2.5 \mathrm{~cm}$ away from the plasma and the two on the right at $5 \mathrm{~cm}$. The upper left picture indicates that the strong debris emission proceeds in a certain solid angle. The transmissions of the glass samples were measured after exposure using the Lambda 900 spectrophotometer (Perkin Elmer prod.). The glass transmissions 
Fig. 10 Witness samples exposed to the EUV source

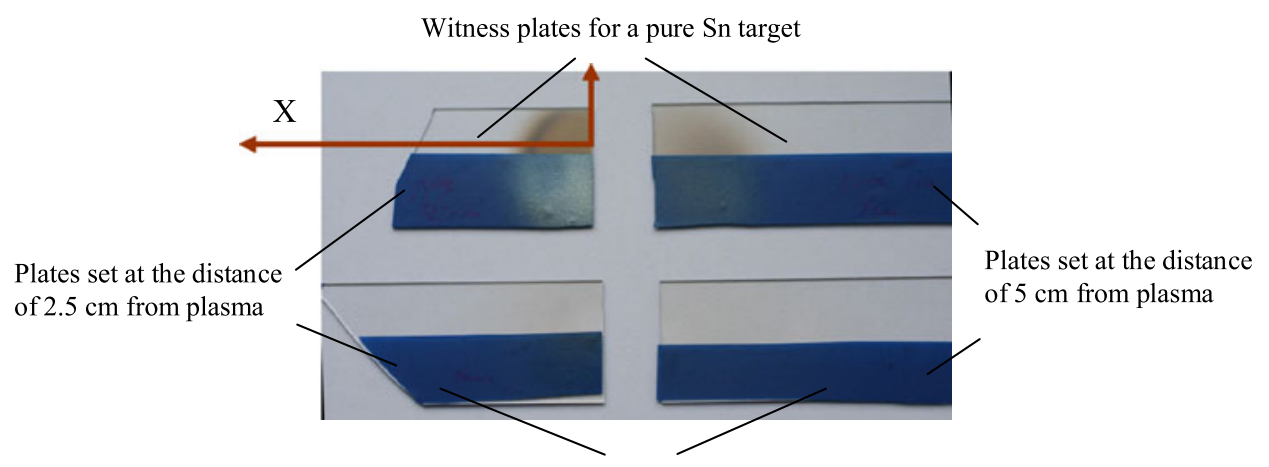

Witness plates for a target consisting of a thin layer of Sn with $\mathrm{LiF}$
Fig. 11 Transmissions of the glass samples in the spectral range $\lambda=0.2-3.2 \mu \mathrm{m}$ : placed at the distance of $2.5 \mathrm{~cm}$ from the tin sheet target (a), at the distance of $5 \mathrm{~cm}$ from the tin sheet target (b), at the distance of $2.5 \mathrm{~cm}$ from the $\mathrm{Sn} / \mathrm{LiF}$ target (c), at the distance of $5 \mathrm{~cm}$ from the $\mathrm{Sn} / \mathrm{LiF}$ target (d)
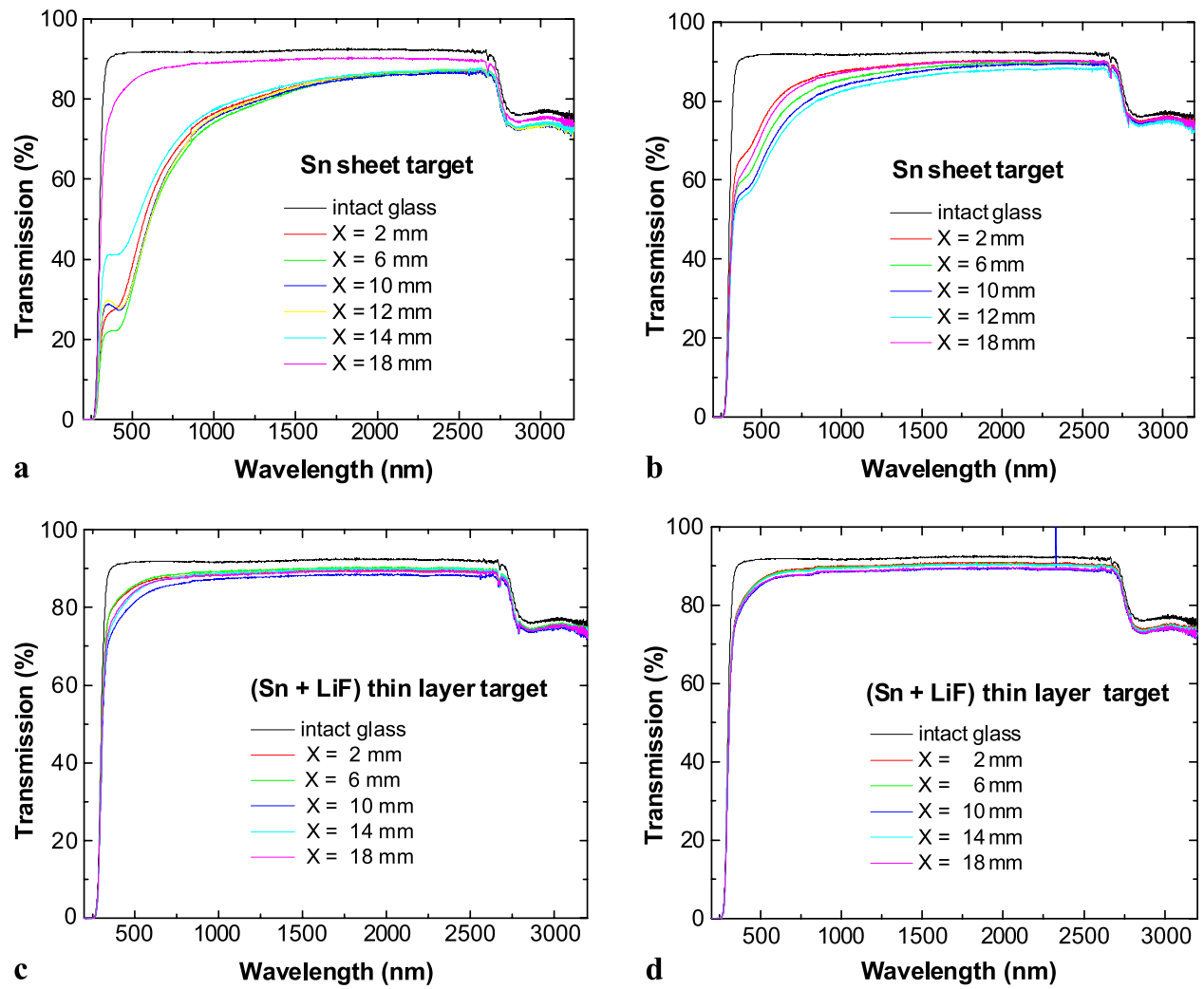

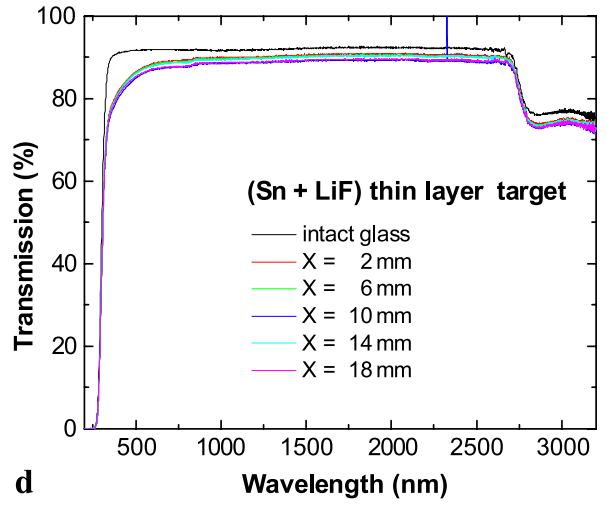

are shown in Fig. 11, and they were measured at various positions along the $X$-axis (marked in Fig. 10).

Scotch tape has been applied to obscure a part of the glass sample to obtain the reference transmission for the intact glass. The position of the center of the aperture of the spectrophotometer was set about $2 \mathrm{~mm}$ above the edge of the scotch tape. In the pure tin target case, the transmission at $\lambda=0.5 \mu \mathrm{m}$ of the witnessed sample placed at the distance of $5 \mathrm{~cm}$ from the plasma decreased to $60 \%$ and to $30 \%$ for the sample placed at $2.5 \mathrm{~cm}$ (for an obscured region on the glass the transmission was $92 \%$ ). For the target consisting of thin $\mathrm{Sn} / \mathrm{LiF}$ layers, the drop in transmission was only a few percent.

The silicon witness sample placed parallel to the target surface (see Fig. 9) was exposed to the plasma debris for
500 laser shots for the $\mathrm{Sn} / \mathrm{LiF}$ target and for 250 shots for the pure tin target, respectively. The surfaces of the silicon samples were scanned using a Multimode STM microscope (Veeco prod.). Figure 12 presents a $5 \times 5 \mu^{2}$ cut-out of the silicon surface topography after debris deposition. The surface is coated with a thin layer of the debris showing the presence of sub-micron droplets.

\section{Conclusion}

In summary, the investigations have shown the advantage of $\mathrm{Sn} / \mathrm{LiF}$ composite targets (higher $\mathrm{CE}$ as well as less debris production) in comparison with the pure tin target. However, 
Fig. 12 Topography of $5 \times 5 \mu \mathrm{m}^{2}$ silicon surface cut-out exposed to the EUV source for 500 laser shots: 3D view of the surface (a), top view (b)

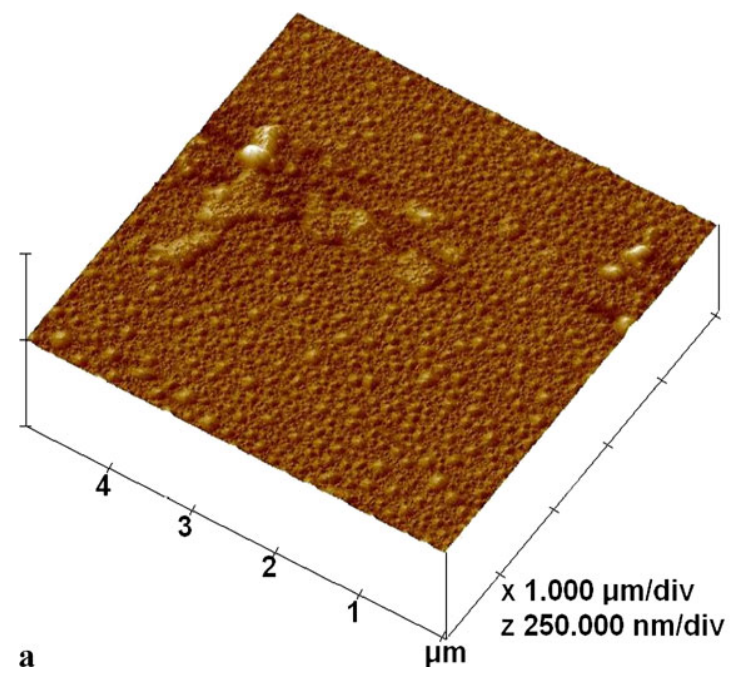

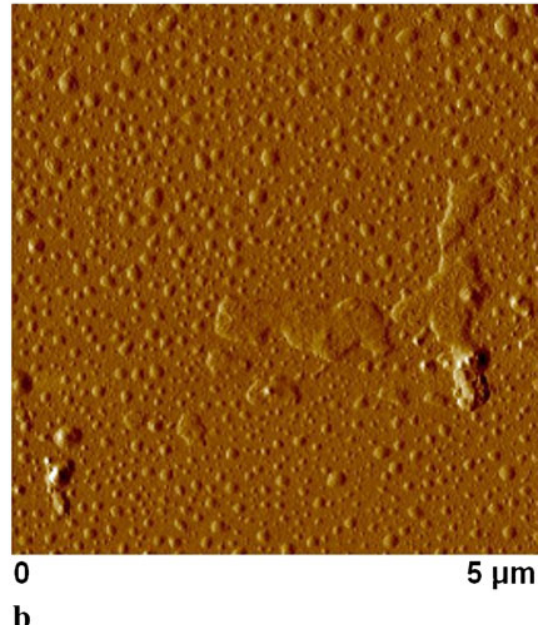

the mitigation system technology has not been fully established yet. A debris-free target solution like a double-stream gas puff target has been rejected due to the CE that was several times lower than that of, e.g., droplet targets based on tin. But in comparison with tin-rich, thin-layer targets, the double-stream gas puff target, due to its intrinsic cleanliness much better meets the requirements for EUV metrology purposes. Our results demonstrate the CE of up to $1.5 \%$ versus the required $3 \%$ for EUV lithography. Some other researches indicate that the $\mathrm{CO}_{2}$ laser is the better option than the Nd:YAG laser, gaining both in a higher EUV yield and a lower debris production from tin-rich targets. One of the groups concerned with EUV sources reported that for a tin plate target $4.5 \% \mathrm{CE}$ has been obtained just by using the $\mathrm{CO}_{2}$ laser instead of Nd:YAG, for which $1.5 \% \mathrm{CE}$ had been previously measured [56]. However, the EUV optics lifetime problem still remains to be overcome [59]. Presumably application of the in-situ mirror cleaning method will be also needed to maintain the desired long life time of EUV optics [59]. An interesting option is to combine the $\mathrm{Sn} / \mathrm{LiF}$ composite target coated on tape with a relevant target refreshing system and the highly repetitive $\mathrm{CO}_{2}$ laser.

Acknowledgements The research was performed under the European MEDEA + programme and was funded by the State Committee for Scientific Research of Poland (Grant No72/E-67/SPB/5.PR UE/DZ 27/2003-2005).

Open Access This article is distributed under the terms of the Creative Commons Attribution Noncommercial License which permits any noncommercial use, distribution, and reproduction in any medium, provided the original author(s) and source are credited.

\section{References}

1. V.Y. Banine, J.P.H. Benschop, H.G.C. Werij, Microelectron. Eng. 53, $681(2000)$
2. U. Stamm, J. Phys. D, Appl. Phys. 37, 3244 (2004)

3. J. Jonkers, Plasma Sources Sci. Technol. 15, S8 (2006)

4. S. Wurm, Solid State Technol., October 2006. Online http:// downloads.pennet.com/pnet/misc/sst/sstonlineaoct06.pdf

5. V. Banine, R. Moors, J. Phys. D, Appl. Phys. 37, 3207 (2004)

6. J. Bauche, C. Bauche-Arnoult, M. Klapisch, Phys. Scr. 37, 659 (1988)

7. D. Attwood, Soft X-Rays and Extreme Ultraviolet Radiation: Principles and Applications (Cambridge University Press, Cambridge, 2000)

8. R.C. Spitzer, T.J. Orzechowski, D.W. Phillion, R.L. Kauffman, C. Cerjan, J. Appl. Phys. 79, 2251 (1996)

9. H. Azuma, Y.Y. Nishimura, A. Sakata, A. Takeuchi, Appl. Surf. Sci. 197-198, 224 (2002)

10. P. Hayden, P. Sheridan, G. O'Sullivan, P. Dunne, L. Gaynor, N. Murphy, A. Cummings, Proc. SPIE 5826, 154 (2005)

11. G. O'Sullivan, A. Cummings, P. Dunne, P. Hayden, L. McKinney, N. Murphy, J. White, in EUV Sources for Lithography, ed. by V. Bakshi (SPIE, Bellingham, 2006). Chap. 5

12. P. Hayden, A. Cummings, L. Gaynor, N. Murphy, G. O'Sullivan, P. Sheridan, E. Sokell, J. White, P. Dunne, Proc. SPIE 5751, 919 (2005)

13. P. Hayden, A. Cummings, N. Murphy, G. O'Sullivan, P. Sheridan, J. White, J. Appl. Phys. 99, 093302 (2006)

14. P. Hayden, J. White, A. Cummings, P. Dunne, M. Lysaght, N. Murphy, P. Sheridan, G. O’Sullivan, Microelectron. Eng. 83, 699 (2006)

15. P. Dunne, G. O’Sullivan, D. O’Reilly, Appl. Phys. Lett. 76, 34 (2000)

16. Y. Tao, M.S. Tillack, S.S. Harilal, B. O'Shay, F. Najmabadi, Report no. UCSD-CER-05-07, University of California, San Diego (2005)

17. T. Mochizuki, C. Yamanaka, Proc. SPIE 733, 23 (1987)

18. H. Fiedorowicz, A. Bartnik, R. Jarocki, R. Rakowski, M. Szczurek, Appl. Phys. B 70, 305 (2000)

19. M. Richardson, C.-S. Koay, C. Keyser, K. Takenoshita, E. Fujiwara, M. Al-Rabban, Proc. SPIE 5196, 119 (2004)

20. D.W. Myers, I.V. Fomenkov, B.A.M. Hansson, B.C. Klene, D.C. Brandt, Proc. SPIE 5751, 248 (2005)

21. H. Shields, S.W. Fornaca, M.B. Petach, M. Michealian, R.D. McGregor, R.H. Moyer, R.S. Pierre, Proc. SPIE 4688, 94 (2002)

22. A. Sunahara, Numerical analysis of extreme ultra-violet emission from laser-produced tin plasmas. Poster at http://www.sematech. org/meetings/archives/litho/euvl/20041101 euvl/posters/SoP50 Sunahara.pdf (2004) 
23. A. Cummings, G. O'Sullivan, P. Dunne, E. Sokell, N. Murphy, J. White, J. Phys. D, Appl. Phys. 38, 604 (2005)

24. T. Krücken, K. Bergmann, L. Juschkin, R. Lebert, J. Phys. D, Appl. Phys. 37, 3213 (2004)

25. K. Takenoshita, C.-S. Koay, S. Teerawattanasook, M.C. Richardson, Proc. SPIE 5374, 954 (2004)

26. B.M. Mertens, B. van der Zwan, P.W.H. De Jager, M. Leenders, H.G.C. Werij, J.P.H. Benschop, A.J.J. Van Dijsseldonk, Microelectron. Eng. 53, 659 (2000)

27. B. Mertens, M. Weiss, H. Meiling, R. Klein, E. Louis, R. Kurt, M. Wedowski, H. Trenkler, B. Wolschrijn, R. Jansen, A. Van de Runstraat, R. Moors, K. Spee, S. Plöger, R. Van de Kruijs, Microelectron. Eng. 73-74, 16 (2004)

28. H.A. Bender, D. O'Connell, W.T. Silfvast, Appl. Opt. 34, 6513 (1995)

29. J. Jonkers, in Proc. XXVIIth ICPIG (2005)

30. F. Bijkerk, E. Louis, M.J. van der Wiel, I.C.E. Turcu, G.J. Tallents, D. Batani, J. X-ray Sci. Technol. 3, 133 (1992)

31. R. Bobkowski, R. Fedosejevs, J. Vac. Sci. Technol. A 14, 1973 (1996)

32. I.C.E. Turcu, J.B. Dance, X-rays from Laser Plasmas (Wiley, New York, 1998)

33. L. Rymell, H.M. Hertz, Rev. Sci. Instrum. 45, 4916 (1995)

34. P.A.C. Jansson, B.A.M. Hansson, O. Hemberg, M. Otendal, A. Holmberg, J. de Groot, H.M. Hertz, Appl. Phys. Lett. 84, 13 (2004)

35. T. Aota, T. Toshihisa, Phys. Rev. Lett. 94, 015004 (2005)

36. K. Nishihara, K. Fujima, H. Furukawa, K. Gamada, T. Kagawa, Y.G. Kang, T. Kato, T. Kawamura, F. Koike, R. More, M. Murakami, T. Nishikawa, A. Sasaki, A. Sunahara, H. Tanuma, V. Zhakhovskii, H. Nishimura, T. Okuno, Y. Shimada, S. Uchida, S. Fujioka, Y. Tao, N. Miyanaga, Y. Izawa, T. Obara, C. Suzuki, in Proc. 4th International Conference on Atomic and Molecular Data and Their Applications (ICAMDATA), Toki, Japan, 5-8 October 2004

37. W. Choi, H. Daido, S. Yamagami, K. Nagai, T. Norimatsu, H. Takabe, M. Suzuki, T. Nakayama, T. Matsui, J. Opt. Soc. Am. B 17, 1616 (2000)

38. Y. Shimada, H. Nishimura, M. Nakai, K. Hashimoto, M. Yamaura, Y. Tao, K. Shigemori, T. Okuno, K. Nishihara, T. Kawamura, A. Sunahara, T. Nishikawa, A. Sasaki, K. Nagai, T. Norimatsu, S. Fujioka, S. Uchida, N. Miyanaga, Y. Izawa, C. Yamanaka, Appl. Phys. Lett. 86, 051501 (2005)

39. M. Richardson, C.-S. Koay, K. Takenoshita, C. Keyser, J. Vac. Sci. Technol. B 22, 785 (2004)

40. C.-S. Koay, Ch.K. Keyser, K. Takenoshita, E. Fujiwara, M.M. AlRabban, M. Richardson, I.C.E. Turcu, H. Rieger, A. Stone, J.H. Morris, Proc. SPIE 5037, 801 (2003)

41. L.A. Shmaenok, C.C. De Bruijn, H.F. Fledderus, R. Stuik, A.A. Schmidt, D.M. Simanovski, A.V. Sorokin, T.A. Andreeva, F. Bijkerk, Proc. SPIE 3331, 90 (1998)

42. K. Takenoshita, C.-S. Koay, M.C. Richardson, I.C.E. Turcu, Proc. SPIE 5037, 792 (2003)
43. H. Yashiro, T. Aota, K. Nishigori, Y. Ueno, T. Tomie, Proc. SPIE 5037, 759 (2003)

44. F. Bijkerk, L.A. Shmaenok, A.P. Shevelko, R.K.F.J. Bastiaensen, C. Bruineman, A.G.J.R. van Honk, Microelectron. Eng. 27, 299 (1995)

45. B.M. Mertens, B. van der Zwan, P.W.H. De Jager, M. Leenders, H.G.C. Werij, J.P.H. Benschop, A.J.J. Van Dijsseldonk, Microelectron. Eng. 53, 659 (2000)

46. K. Yukimura, Surf. Coat. Technol. 136, 1 (2001)

47. N. Harned, Progress on realization of EUV lithography. Presentation at http://www.sematech.org/meetings/archives/litho/ euv1/7470/Presentations/03201-ET-1120Harned.pdf

48. P.A. Grunow, Proc. SPIE 5037, 418 (2003)

49. A. Endo, H. Hoshino, T. Suganuma, M. Moriya, T. Ariga, Y. Ueno, M. Nakano, T. Asayama, T. Abe, H. Komori, G. Soumagne, H. Mizoguchi, A. Sumitani, K. Toyoda, Laser produced EUV light source development for HVM. Presentation at https://www.gigaphoton.com/e/pdf_files/6517-23_LPP40W_ Presentation.pdf

50. K. Wakana, T. Abe, Y. Watanabe, T. Ishihara, T. Hori, T. Ohta, A. Kurosu, H. Komori, H. Nakarai, K. Kakizaki, A. Sumitani, J. Fujimoto, H. Mizoguchi, Future of high power EUV sources. Presentation at http://www.euvlitho.com/2010/ ABSTRACTS\%202010\%20EUVL\%20Workshop.pdf

51. A. Endo, H. Komori, Y. Ueno, K.M. Nowak, Y. Takayuki, Y. Tatsuya, T. Suganuma, T. Asayama, H. Someya, H. Hoshino, M. Nakano, M. Moriya, T. Nishisaka, T. Abe, A. Sumitani, H. Nagano, Y. Sasaki, S. Nagai, Y. Watanabe, G. Soumagne, T. Ishihara, O. Wakabayashi, K. Kakizaki, H. Mizoguchi, Proc. SPIE 7271, 727108 (2009)

52. G. O’Sullivan, A. Cummings, P. Dunne, K. Fahy, P. Hayden, L. McKinney, N. Murphy, E. Sokell, J. White, AIP Conf. Proc. 771, 108 (2005)

53. A. Sasaki, A. Sunahara, K. Nishihara, T. Nishikawa, F. Koike, H. Tanuma, J. Phys. Conf. Ser. 163, 012107 (2009)

54. H. Tanaka, A. Matsumoto, K. Akinaga, A. Takahashi, T. Okada, Appl. Phys. Lett. 87, 041503 (2005)

55. A. Endo, Performance and concepts of EUVA LPP and GDPP technologies. Presentation at http://www.sematech.org/ meetings/archives/litho/euvl/20050227/pres/04Endo.pdf

56. A. Endo, H. Hoshino, T. Ariga, T. Miura, Y. Ueno, M. Nakano, H. Komori, G. Soumagne, H. Mizoguchi, A. Sumitani, K. Toyoda, Development status of HVM laser produced plasma EUV light source. Presentation at http://www.sematech.org/meetings/ archives/litho/7870/proceedings/oral/D2/3SO05\%20Endo.pdf

57. T. Kita, T. Harada, N. Nakano, H. Kuroda, Appl. Opt. 22, 512 (1983)

58. N. Nakano, H. Kuroda, T. Kita, T. Harada, Appl. Opt. 23, 2386 (1984)

59. K. Kemp, S. Wurm, C. R. Phys. 7, 875 (2006) 